\title{
La subversión de conciencia en Rosario Castellanos: un acercamiento didáctico a "Lección de cocina"
}

\section{Subversion of consciousness in Rosario Castellanos: a didactic approach to "Lección de cocina"}

\author{
Elia Saneleuterio \\ Universitat de València (España) \\ University of California, Berkeley (USA) \\ elia.saneleuterio@uv.es
}

Resumen: "Lección de cocina", de Rosario Castellanos, se construye en forma de fluir de conciencia de una recién casada mientras asa dos filetes. El discurso se entremezcla con sus propias experiencias culturales, conyugales y con el ardor de las quemaduras solares sufridas en la luna de miel. Los pensamientos se subvierten en consonancia con el propio proceso de cocción de los alimentos, que también van quemándose por su inexperiencia culinaria. Se estructura como respuesta un entretejido simbólico: carne asada como correlato de la propia carne, del coito y de la acción literaria, especialmente en lo que afectan a la identidad de la mujer. Esta triple caracterización sustenta las pautas que proponemos para el acercamiento a este relato, desde una perspectiva didáctica, que trasciende lo literario, pues cada uno de estos estratos se encuentra sazonado por la opresión de la sociedad mexicana hasta mediados del siglo xx.

AвSTRACT: A newlywed woman's stream of consciousness, while roasting two steaks, structures Rosario Castellanos' "Lección de cocina". The speech is interspersed with her own culture, marital experiences and sunburn suffered during the honeymoon. Thoughts are subverted at the same time the food is cooked, which is also burned because of her culinary inexperience. All of this results in a symbolic interweaving: roast beef as correlative of flesh, intercourse and literary action, especially insofar as these affect women. This triple characterization supports my proposal for reading this story from an educational perspective, not only literary, since each layer is seasoned by the oppression in Mexican society

Palabras Clave: símbolo; formación literaria; cuerpo; feminismo; narrativa mexicana.

KEYWORDS: symbol; literary training; body; feminism; Mexican narrative.

FeCHA De RECEPCIÓn: 2 de agosto de 2016.

FECHA DE ACEPTACIÓn: 26 de septiembre de 2016. 
“ Cección de cocina" es un relato de la escritora mexicana Rosario 7 de agosto de 1974) narrado en forma de monólogo interior, el que sostiene consigo misma una recién casada mientras intenta preparar dos trozos de carne en la sartén, su primera comida conyugal, su primera demostración culinaria, su primer fracaso. El discurso se entremezcla con sus propias experiencias sexuales, así como con su sufrimiento carnal al haberse quemado su piel por el sol durante la reciente luna de miel, para terminar con todo un alegato por la cofradía de mujeres mexicanas que la precedieron.

"Lección de cocina" forma parte, junto con tres relatos más, del libro titulado Álbum de familia, publicado en México en 1971, y relativamente celebrado por la crítica posterior por su ironía, su aguda narrativa y su feminismo capaz de impregnar de crítica tanto las desigualdades y contradicciones más evidentes como las más sutiles que afectaban a la mujer mexicana que intentaba buscar su lugar en un ambiente urbano supuestamente avanzado y liberador (Ocampo, Fishburn, Luongo, Carpenter, Martínez, Popovic, Soria).

\section{MODALIZACIÓN NARRATIVA}

Desde el punto de vista comunicativo, el estrato enunciativo superficial, el más evidente, es la descripción del proceso de cocción de los filetes mediante la técnica narrativa del flujo de conciencia. Sin embargo, en el hilo monologado que compone el relato, los pensamientos se entrecruzan, como en un concierto, con el propio proceso de cocción de la comida: los niveles enunciativos de recuerdo de los primeros coitos, de la propia relación de pareja y del ahora en la cocina, aunque no coincidentes temporalmente, se encuentran en la enunciación del relato en perfecta sinfonía. El desenlace de todos ellos viene determinado por el hecho de que la carne - la de los filetes, pero también, simbólicamente, la de los otros dos niveles descritos- va quemándose poco a poco ante la impotencia de la cocinera.

Respecto de la modalización espacial, la cocina de este primer cuento de Álbum de familia no aparece caracterizada con los atributos propios del imaginario tradicional, como cubículo exclusivo del ángel del hogar, lugar de realización personal y familiar de toda mujer, 
que Castellanos trata con ironía, más o menos desarrollada, en toda su producción, y especialmente en su obra tardía (Fishburn: 97-98). Como punto de partida para la transposición irónica, la protagonista, en un primer momento, se siente coaccionada a representar ese papel, a asumir la función de chef al servicio de los demás; esa es la educación que recibe la mujer, la herencia sabia de sus madres, como expresa la escritora en un poema escrito por esas fechas, "Economía doméstica" (Castellanos 1972: 300-302). Obediente a ese legado educativo que le corresponde por sexo, incluso intenta asumir ese rol: "mi lugar está aquí. Desde el principio de los tiempos ha estado aquí. En el proverbio alemán la mujer es sinónimo de küche, kinder, kirche"(1971:7), afirma en la primera página de "Lección de cocina", ligando su identidad al alma mater de la casa. Fuera de la cocina está el afuera, el espacio que no le es lícito ocupar a la mujer: "Yo anduve extraviada en aulas, en calles, en oficinas, en cafés, desperdiciada en destrezas que ahora he de olvidar para adquirir otras. Por ejemplo, elegir el menú. ¿Cómo podría llevar al cabo labor tan ímproba sin la colaboración de la sociedad, de la historia entera?" (7).

El espacio que se construye narrativamente, en su diseño moderno, es todo lo contrario al recuerdo maternal de los pucheros: es blanca y reluciente, neutra de reminiscencias. Y aquí vendrían las primeras impresiones simbólicas que se pueden desprender de esa impecabilidad inodora: la cocina es nueva, pues sus habitantes, recién casados, acaban de estrenar la vivienda, símbolo a su vez de una recién estrenada relación. Todo podría ser nuevo, escrito en tabula rasa. No obstante, los mismos sujetos, incluida la mujer en un primer momento, deciden sumarse a los usos sociales convenidos, pero no por ello menos perversos; la luna de miel, sobre la que reflexiona la enunciadora, sería el primer síntoma de ello, el primer paso torcido para encaminar el nuevo matrimonio.

Así, la blancura de los muebles y de las paredes se vuelve un símbolo en contra del propio deseo de renovar las relaciones entre los sexos, y su desinfección acaba simbolizando, en la línea de los hospitales, la inminencia de algo oscuramente negativo, pero brillantemente irónico:

${ }^{1}$ Virginia Woolf reclamaba espacio propio para la mujer, que ella misma había de buscar y territorializar. El término "territorio", como lo entienden Gilles Deleuze y Félix Guattari (321), sería un acto, más que un mero lugar. Cfr. Saneleuterio (2010b; 2010c). 
La cocina resplandece de blancura. Es una lástima tener que mancillarla con el uso. Habría que sentarse a contemplarla, a describirla, a cerrar los ojos, a evocarla. Fijándose bien esta nitidez, esta pulcritud carece del exceso deslumbrador que produce escalofríos en los sanatorios. ¿O es el halo de desinfectantes, los pasos de goma de las afanadoras, la presencia oculta de la enfermedad y de la muerte? (7).

\section{LA RESPUESTA SIMULADA}

A partir de estas cavilaciones, y ante la negativa (disfrazada de irónica imposibilidad) de aceptar el nuevo rol, la recién casada decide convertirse en una hipócrita - en una maestra del doblez, diría Pol Popovic (92-98), quien considera el delantal como símbolo de este engaño-: simulará todo lo que necesite simular, incluida su reacción ante el marido a causa del incipiente fracaso culinario. Aunque afirma, no sabemos si con sinceridad, que "me repugna actuar asi”" (Castellanos 1971: 21), el hecho es que no le queda otra alternativa que prender fuego a su propia autenticidad. La carne se quema, como ella misma, pero de cómo exprese sus pretendidas disculpas dependerá el concepto que él se forme de su esposa para el resto de vida en común: "Yo seré, de hoy en adelante, lo que elija en este momento" (21). ¿Frívola e irresponsable? ¿Inútil, pero sumisa? Para lo uno debería esconder el intento fallido de cocinar y proponer ingenua, por ejemplo, la visita a un restaurante; para lo segundo debería mostrarse arrepentida y con deseos de complacer el paladar del marido... En todo caso, nadie nos asegura que todo el montaje no sea sino un "plan orquestado desde el principio" (Popovic: 95), con lo que retornaríamos a la profunda ironía de Castellanos. Según Nuria Girona (127), podríamos definir todo el proceso dentro de la tradición de estrategias femeninas de camuflaje para fabricarse un ser que parezca "ser lo que no es".

Hacia el final de En la tierra de en medio (Castellanos 1972), un poemario sobre la maternidad y la triple responsabilidad de la mujer como madre, trabajadora fuera del hogar y al mismo tiempo ama de casa, Rosario Castellanos incluye un poema que se titula "Lecciones de cosas" (307-310). Aparte de la evidente intertextualidad establecida a nivel de paratexto, este poema conecta con el relato que nos ocupa por presentar el mismo movimiento de conciencia femenina que conduce al sujeto, 
desde un primer intento por aprender, creer y poner en práctica las lecciones que los otros imponen injustificadamente, a una liberación de esa imposición, una deliberada opción de "escaquearse", mezclada de la certeza de que, siendo realista con el tiempo que le tocó vivir, debía hacerlo "disimuladamente". Estoy convencida de que esa necesidad de sutileza explica la profunda ironía que caracteriza toda la obra de Rosario Castellanos. Por eso, queda evidente que "Lección de cocina" no es una lección de cocina. Sin embargo, atesora grandes reflexiones para la coeducación, interesantes desde un punto de vista literario dado que se producen como resultado de una construcción simbólica magistralmente tejida. Precisamente esos dos polos son los que hacen del relato un ejemplo idóneo para la educación de los jóvenes lectores, con el gancho de lo subversivo, punto fuerte de la buena literatura infantil y juvenil (Lurie 1998), e incluso de literatura como sabotaje de la crítica adulta (Asensi: 104).

Veamos cómo podemos, a efectos de la educación literaria, aislar en cuatro dimensiones simbólicas lo que el incidente de la carne, argumentalmente eficaz, representa en un nivel de significación que el propio discurso sugiere.

\section{Primer NiVEL SIMBÓliCO:}

LAS QUEMADURAS SOLARES SUFRIDAS EN LA PROPIA ESPALDA

El cambio de estado de los bistecs tiene que ver, en un primer momento, con la carne de la protagonista, escaldada por el sol durante el viaje de novios. Ese es el primer flashback que le produce la carne roja, con su frescura evanescente en el asador. "¿Qué rayos pasa? Esta maldita carne está empezando a echar un humo negro y horrible. ¡Tenía yo que haberle dado la vuelta! Quemada de un lado. Menos mal que tiene dos" (Castellanos 1971: 18). También ella tiene dos lados, pero el lado sano parece ser ignorado por su compańero, dado que elige la postura del misionero para hacer el amor.

\section{SEgUNdo NIVEl SIMbÓlico: El ACTO SEXUAL COMO SACRIFICIO}

Efectivamente, el correlato carnal se vuelve mucho más profundo cuando se establece con la carne entendida como objeto sexual; su cuerpo, 
ya asado, como juguete para volver a arder a disposición de la pasión carnal del marido, a quien parecen no importarle las molestias de las quemaduras de la piel de su mujer por la fricción y el contacto con las sábanas: "él podía darse el lujo de 'portarse como quien es' y tenderse boca abajo para que no le rozara la piel dolorida” (9). Rescatando el planteamiento que Franco propusiera para este relato en 1984, se trataría de un doble sacrificio por la hoguera, que no deja de ser símbolo, a su vez, de una iniciación sexual frustrante. "Casada" y "asada" serían correlato de una misma historia (Saneleuterio 2010a: 4), que se vive como si definitivamente fuera una sentencia inevitable, y a la que podríamos ahora añadir un tercer término que completara el juego de palabras: "cansada", un cansancio que no se relaciona con el tiempo de matrimonio, dado que éste no ha hecho más que comenzar, sino con el peso de las convenciones sobre la conciencia de la protagonista, quien lo siente como una insoportable carga ahora que lo experimenta en primera persona.

El continuum de pensamiento expresado por la voz narrativa, al traer a colación las relaciones entre los sexos, la conduce a otra asociación. El cazador que consigue su presa para alimentar su estómago hambriento es la base de cierta tópica tradicional: también el hombre se convierte en un cazador que quiere deleitarse con la carne de la hembra que consiga cazar... El vínculo entre gula y lujuria, valor y ataque, subyacente en el relato, se torna ahora explícito, si bien se ironiza sobre él al invertir su sentido: es ella la que, imaginándose sola por la calle, constituye el peligro para "cualquier viandante" (Castellanos 1971: 18). Si la tentadora es la mujer, como se suele argumentar incluso en casos de violación, entonces la peligrosa es la presa, y de ahí la burla de Castellanos, que incluso pone en evidencia las trampas del propio lenguaje que usamos para representarnos mentalmente estos tópicos. El pasaje referido, por la comparación entre dos interpretaciones de la "cacería sexual", se presta al trabajo en el aula de la comprensión lectora, que puede haberse despistado en los movimientos de cruces de significación. Por otro lado, habría que considerar hasta qué punto se trata de "representations of grotesque machismo objectifying women to protect the patriarchal status quo" (Carpenter: 61); ${ }^{2}$ Victoria Carpenter se plantea si el modelo de macho representado en Álbum de familia es realmente opresor

${ }^{2}$ Se refiere a las "representaciones del machismo grotesco que objetiviza a las mujeres para proteger el status quo patriarcal" (traducción mía). 
y la mujer siempre víctima y si es conveniente superar esta dicotomía simplista para acercarnos a un modelo complejo más representativo de la realidad, que es precisamente el que subyace en el legado de Castellanos, tanto literario como ensayístico.

\section{TERCER NIVEL SIMBÓLICO:}

\section{LA METAMORFOSIS DE LA IDENTIDAD FEMENINA}

Volviendo a aquella desafortunada comprensión de la unión carnal del matrimonio de este primer relato, vemos que constituye el origen de su propia desviación: impedida psicológicamente para agarrar la sartén por el mango, el cuerpo de la mujer, como el churrasco, experimenta cambios, y algunos van más allá de la identidad física. Podríamos definirlo como una "metamorfosis profunda" (Castellanos 1971: 12), resultado de su "contacto o colisión con él" y que en algunos países — como es el caso mexicano, contexto cultural de la protagonista que tiene su función narrativa (Ocampo 1985) — comienza por el cambio de apellidos, que ella detesta, pero al que ha accedido sin cuestionarse, incomprensiblemente incluso para ella misma ahora que se da cuenta. ¿A qué obedece esta resignación? A sumisión y humildad no lo parece; a autodisciplina, quizás, aunque no justificada, o en todo caso producida por el ambiente de subyugación general que la protagonista ha vivido o ha observado en su entorno, si no hacia todas las mujeres - pues ella misma nombra estilos de vida que le resultan atrayentes, por su independencia y autonomía en el plano laboral y emocional—, sí en el contexto del matrimonio, que es el que ella misma ha elegido para continuar su vida. Cuando una obra construye personajes profundos, es posible que el lector les atribuya una sicología y un modus operandi según el cual debería ser posible encontrar coherencia en pasajes que no lo evidencian: ese es trabajo que el lector aprende y que constituye un foco de atención para el profesorado de literatura, que debería conseguir su desarrollo en el alumnado.

\section{OTRAS IMPLICACIONES}

Si combinamos los tres niveles simbólicos, podemos retroceder al principio de la transformación. Los filetes del relato, antes de ser so- 
metidos al fuego, son grandes y de un color rojo orgulloso: "Y no es solo exceso de lógica el que me inhibe el hambre. Es también el aspecto, rígido por el frío; es el color que se manifiesta ahora que he desbaratado el paquete. Rojo, como si estuviera a punto de echarse a sangrar" (9). Es la cocción la que los degrada, los ennegrece y empequeñece, humilla su grana escarlata convirtiéndola en un vergonzante y pardo marrón. Esta metamorfosis aparece como una síntesis del relato paralelo: el cuerpo femenino, el matrimonio consumado, desaparece porque sólo era apariencia, como la carne asada, ${ }^{3}$ que cuando el diente la va a morder ha olvidado su jugo, su gracia, su ser: "si yo dejo este trozo de carne indefinidamente puesto al fuego, se consume hasta que no queden ni rastros de él. Y el trozo de carne que daba la impresión de ser algo tan sólido, tan real, ya no existe" (20). Esta reflexión se asocia también con la masculinidad; para Victoria Carpenter (66), el propio bistec es el símbolo del marido: "If we consider the phallic nature of the roast, we can draw a parallel between the meat/man's resistance to change and the defensive nature of masculinity" $(65)^{5}$.

El varón, su esposo, es sólido como el filete crudo, antes de ser sometido. A ella le parece real, pero reconoce que podría ser una trampa. Podría ser un "personaje inventado" (Castellanos 1971: 20), aunque prefiere pensar que nada hay que se desintegre, que desaparezca; las cosas sólo se transforman, aunque algo se vuelva imperceptible "continuará operando en otros niveles. En el de mi conciencia, en el de mi memoria, en el de mi voluntad", porque ha dado el "salto cualitativo" (21).

${ }^{3} \mathrm{La}$ asociación sinecdóquica parte-todo puede compararse con lecturas simbólicas del cuerpo en otros autores. Véase, por ejemplo, Saneleuterio (2009; 2011c).

${ }^{4}$ Ella se basa, siguiendo a parte de la crítica anterior, en la asociación carne rígidapene erecto. Otros planos simbólicos derivados de su análisis, pero en los que no nos vamos a detener, hacen pensar en la necesidad de cuidado del marido, que busca en el matrimonio a la propia madre, siendo el proceso de la cocción símbolo de la maduración (Carpenter: 67). Incluso la fantasía del divorcio le hace pensar a ella que él se tendrá que cuidar solo, momento enunciativo que encuentra, de nuevo, su correlato en la carne cocinada, que en ese momento se encoge y retuerce en la sartén, simbolizando posición fetal.

5 "Si tenemos en cuenta la naturaleza fálica del asado, podemos establecer un paralelismo entre la resistencia al cambio de la carne/hombre y el carácter defensivo de la masculinidad" (traducción mía). 
LA ASTUCIA FEMENINA COMO MARMITA:

BRUJERÍA, INTELECTUALIDAD Y LOCURA

Podemos añadir un cuarto plano simbólico si atendemos la interpretación que Josefina Ludmer (47-54) extrae de su lectura crítica de este relato. Dado que su propuesta tiene que ver con la comida y con las recetas de cocina, podemos aplicarla a la preparación de la carne por parte de la protagonista. Por ello y por su sentido feminista las conexiones de Ludmer pueden resultar útiles en el acercamiento didáctico a la simbolización en "Lección de cocina". Para esta especialista, las "tretas del débil" son diversas, y la recién casada, por razón de su sexo, se encuentra en situación de desventaja respecto al macho, que siempre es visto como el "otro" dominante. Así pues, podemos entender - y hacer entender en el aula - otra vía de escape simbólico: la cocina como refugio, en sí mismo, y específicamente como refugio de la magia y del dominio de las técnicas de envenenamiento para vencer al non grato desde una posición oculta, de servicio. Esto tiene sentido en la medida en que existe una tradición, más arraigada en unas culturas que en otras, de la mujer como cocinera; tiene el dominio de la gastronomía, pero no detenta otro poder que le permita imponer las cosas mediante la fuerza o el sometimiento del otro (Popovic: 97). En nuestro caso, el personaje protagonista, mujer, en efecto se siente débil en su confrontación - física y mental — con su marido, representante del sexo masculino. Sin embargo, no llega a dominar las técnicas culinarias que podrían salvarla de la sumisión; quizás por eso la ironía respecto de haber estado perdiendo el tiempo por no haber intentado antes aprender a cocinar puede leerse como una afirmación oscuramente sarcástica: "Yo anduve extraviada en aulas, en calles, en oficinas, en cafés, desperdiciada en destrezas que ahora he de olvidar para adquirir otras" (Castellanos 1971: 7).

Aquí entra a jugar un papel relevante el imaginario de la brujería y su estrecha relación con la comida y la preparación de platos traidores y pócimas; la propia Castellanos disemina pistas en este sentido, también en otras obras no directamente relacionadas con estos menesteres (Castellanos 1975: 55; 141; 200). Estamos ante todo un saber ligado especialmente a la figura femenina, con la consecuente amenaza de ser acusada de bruja; se trataba de una sospecha continua que pesaba sobre toda mujer, por el hecho de serlo, especialmente en ciertas sociedades 
antiguas, pero todavía en el México de Castellanos. Este cultivo específico del saber gastronómico y sus propiedades no sólo va orientado al logro del objetivo deseado, sino también a la eliminación de obstáculos o enemigos, como explica, en su brillante análisis del relato que nos ocupa, Gilda Luongo Morales. Y es precisamente este último deseo femenino el que se sugiere débilmente en "Lección de cocina", cuando se habla de la viudez femenina como estado relacionado con el saber culinario. Si vamos más allá, podemos incluso leerlo en clave de necesaria renovación, de sazonamiento del saber:

Así pues, según la propuesta de Rosario Castellanos, frente al aburrimiento del saber masculino, ya tan arcaico, sin novedad más que en sus sucesivas yuxtaposiciones, emerge la mujer sabia, intelectual, como la verdadera salsa de los saberes: que vuelve sobre lo ya aceptado comúnmente para desencajarlo, que ridiculiza las convenciones con una pátina de sarcasmo, que se come los latines mojaditos en salsa (Saneleuterio 2011a: 583).

La entrada de la mujer en los ámbitos intelectuales supone una necesaria deconstrucción de los mismos. Teniendo en cuenta que la autoridad sobre estos ámbitos, hasta el momento, la venían ostentando hombres, la reacción de éstos ante cualquier sutil amenaza no es precisamente de acogimiento, sino de rechazo. En este proceso de desautorización del saber femenino, el canon dominante ha establecido dos polos: el primero, directo, la declaración de la locura que anulaba en el destinatario la posibilidad de credibilidad y que ha constituido durante generaciones una amenaza similar a la de la brujería, y que también podía afectar a cualquier mujer cuyos actos parecieran mínimamente sospechosos — sospechosos no de locura, o brujería, sino sospechosos por lúcidos, feministas, inteligentes o poderosos-: " $\mathrm{Si}$ insisto en afirmar mi versión de los hechos mi marido va a mirarme con suspicacia, va a sentirse incómodo en mi compañía y va a vivir en la continua expectativa de que se me declare la locura" (Castellanos 1971: 22). Instalarse en la propia "versión de los hechos" equivale a persistir en ese dominio femenino que se asimila a la locura, en cuanto a versión siempre sospechosa de existir con total independencia de la realidad: 
Este lugar de pérdida del principio de realidad constituye un elemento recurrente en la escritura de Castellanos. La elaboración de esta temática pasa por sentir que somos las mujeres quienes estamos cercanas a la alucinación, al desequilibrio entre realidad y deseo, a la persecución y al delirio por el abandono y el desamor (Luongo 2001).

Locura y liberación de las ataduras, alucinación y libertad, son relaciones que poéticamente se han establecido en literaturas de tradiciones muy dispares, desde la hindú a la hispánica (Saneleuterio 2011b); esta vertiente positiva, desprovista de ligaduras con la feminidad, es la que se quiere recuperar y superponer sobre el binomio mujer-locura por una razón: para que no se convierta en una amenaza a las necesidades básicas (Maslow: 35-47).

\section{EL LIBRO DE RECETAS COMO INTERTEXTO}

Paralelamente a la creación de un imaginario de simulación y dominio gastronómico cuyo legado no acaba de asumir, pero tampoco de rechazar, la narradora aborda otro polo: la existencia de ámbitos escriturales femeninos. Dentro de las escrituras de mujeres, según algunas categorizaciones, encontramos los recetarios, género que ha interesado a Rosario Castellanos no por su función primera, sino por sus implicaciones en la relación entre sexos. En la obra de teatro El eterno femenino, por ejemplo, Lupita prohíbe a las tertulianas hablar de ese tema por ser impropio de una reunión cultural como la que va a tener lugar (Castellanos 1975: 180).

El hecho es que el género discursivo de la receta se deconstruye en "Lección de cocina". Frente al contexto, podemos recuperar la noción barthiana de intertexto: diáspora donde no se cierra ningún camino, encrucijada donde todos son posibles en la medida en que cada uno, simultánea o alternativamente, puede emerger en el texto, siempre que el lector lo active (Barthes, en Thibaudeau: 64). El uso que de la receta que lee realiza la protagonista no es el propio de un documento perteneciente a ese género discursivo, sino que más acertadamente resulta cercano a la intelectualidad. Si bien el libro de recetas tradicionalmente -aunque no siempre, y cada vez menos - abre una esfera de quehaceres domésticos escrito por y para mujeres, la travesía que se emprende 
nos acerca al libro de cocina desde una lectura crítica: "Pero ¿a quién se supone usted que se está dirigiendo? Si yo supiera lo que es estragón y ananá no estaría consultando este libro porque sabría muchas otras cosas" (Castellanos 1971: 8). La recién casada critica un discurso que no tiene razón de ser si sólo va dedicado a las que ya están "en el ajo": "Yo, por lo menos, declaro solemnemente que no estoy, que no he estado nunca ni en este ajo que ustedes comparten ni en ningún otro. Jamás he entendido nada de nada" (8). La declaración de ignorancia es en realidad una postura de rebeldía: por supuesto que ella entiende de muchos asuntos, pero el problema es que no se ha dedicado a lo convencionalmente femenino. De hecho, es capaz de criticar, de nuevo refiriéndose al recetario, ciertos consejos que le parecen inútiles: "Eso se me ocurre hasta a mí, no había necesidad de gastar en esas recomendaciones las páginas de un libro" (16). Un exceso de información que contrasta con la falta de especificidad en otros casos: "Tarda muy poco, dicen los manuales. ¿Cuánto es poco? ¿Quince minutos? ¿Diez? ¿Cinco? Naturalmente, el texto no especifica. Me supone una intuición que, según mi sexo, debo poseer pero que no poseo, un sentido sin el que nací que me permitiría advertir el momento preciso en que la carne está a punto" (13).

Supuesta aprendiz de chef, la protagonista, que en realidad detesta ese rol para sí misma, recurre a otras tretas del débil para lograr su propósito. Y se refiere explícitamente a la "sinuosa vía que recorrieron mis antepasadas, las humildes" (21), es decir, la astucia de los ancestros femeninos, capaz de darle la vuelta a la situación mediante la autohumillación aparente para conseguir, en realidad, dominar al marido. Ella misma cavila sobre las consecuencias de sus posibles roles y reacciones, llegando a identificarse con sor Juana Inés de la Cruz por su neurotismo caviloso.

\section{BUSCANDO LA ESCRITURA AUTÉNTICA FEMENINA}

Partiendo de las sugerencias del estudio de Julia Cuervo Hewitt, considero que la alusión a sor Juana conlleva más que un simple dato anecdótico. A pesar del efecto de oralidad que, enunciativamente, produce el fluir de conciencia de la recién casada, la referencia a sor Juana la inserta, como escritora, además de como lectora y (re)creadora del texto, 
dentro de una genealogía bien diferente: la de las mujeres escritoras hispanoamericanas que se han intentado desmarcar tanto de la tradición de roles sociales femeninos como de las convenciones impuestas por un canon literario masculino.

En este sentido, Lucía Fox-Lockert se refiere al empeño de la escritora por buscar "su ser auténtico en contraste con la imagen femenina que se le había impuesto socialmente" (Fox-Lockert: 461): como mujer, la autora intenta hacer chocar en el relato ambas imágenes, la convenida por los roles sociales y el deseo de liberación de tales ataduras, conflicto que sólo encuentra una salida simbólica en "Lección de cocina": el churrusco carnal, que completa las esferas simbólicas que anunciábamos y sus ramificaciones respecto de la feminidad en la obra de Castellanos.

\section{LA LECTURA FEMINISTA Y LAS CUESTIONES DE GÉNERO EN LA EDUCACIÓN LITERARIA}

La lectura feminista y las cuestiones de género que este relato aporta para la educación literaria, en realidad surgen como consecuencia del planteamiento crítico de los contenidos simbolizados estudiados durante el análisis literario del relato, en sus diferentes estratos de significación.

Mediante la identificación del proceso constructivo de la carne como símbolo múltiple en "Lección de cocina", surge una interesante dimensión, transversal al currículo, pero no menos relevante para la educación: las lecturas del cuerpo y la feminidad, los roles y la relación entre sexos. En el caso español, este interés surgió de manera explícita en la educación ya hacia los años ochenta, con el movimiento coeducativo que pretendía desterrar el sexismo en las aulas, si bien no se afianzaría hasta mucho después, como demuestra Marina Subirats (89-97): será a partir de 2004, cuando se incluirán medidas legislativas, teóricamente promovidas desde la investigación universitaria (9799) y que siguen preocupando en la actualidad (López-García-Torres y Saneleuterio). Pues bien, en este contexto, extrapolable a la realidad educativa de muchos otros países, enraizamos la presente propuesta.

La reflexión que se teje en este cuento de Álbum de familia está relacionada con el planteamiento de hasta qué punto las cosas tienen que ser necesariamente como se sienten y describen; la protagonista 
ha aceptado ciertas funciones "de acuerdo con la imagen que le ha sido indoctrinada desde que nació" (Fox-Lockert: 464), pero la propia Castellanos se enfrenta a esa imposición, en boca de la recién casada, e imagina que otro reparto es posible: "Para la siguiente película me gustaría que me encargaran otro papel. ¿Bruja blanca en una aldea salvaje? No, hoy no me siento inclinada ni al heroísmo ni al peligro. Más bien mujer famosa (diseñadora de modas o algo así), independiente y rica que vive sola en un apartamento en Nueva York, París o Londres" (1971: 17).

No es insólita, ni exclusiva de este relato, la preocupación de Rosario Castellanos por la educación de las mujeres (Ocampo 1985) y por la evolución del concepto de mujer:

Las ideas sobre la liberación femenina que Castellanos deja entrever con mordaz ironía desde la ficción aparecen al tiempo teorizadas y claramente expuestas en una serie de textos periodísticos que versan sobre el papel de la mujer a lo largo de la historia y en los diferentes países, para ir centrándose en el caso mexicano, artículos que la escritora publicó de manera conjunta, dos años más tarde, en el compendio Mujer que sabe latín... (1973). Una de las conclusiones más relevantes a la que en ellos se llega es que si, por un lado, parece que en la época las mujeres tenían el mismo acceso a la educación formal que los hombres, por otro lado, no gozaban de las mismas oportunidades para ejercer su profesión, y mucho menos credibilidad o fiabilidad (Saneleuterio 2010a: 1).

En "La mujer y su imagen" (Castellanos 1973: 9-21), la autora sistematiza el proceso de anulación de la mujer que se ha trazado a lo largo de la historia, y lo más interesante es que consigue superar la dicotomía opresor-víctima para hablar de la lectura del otro. Si la voz la tenía el hombre, necesariamente la mujer no podía decirse a sí misma ni asumir otro rol que no fuera, precisamente, el de antagonista. Y aquí viene una de las críticas más mordaces que se han hecho a ciertas ramas del Feminismo (Naomi Lindstrom; Ángela Aparisi). Victoria Carpenter (64) acusa a las propias mujeres, o a parte de ellas, de perpetuar el orden patriarcal preservando y perseverando la dicotomía dominante-subyugada en las relaciones de género, que sería lo que en un primer momento hace la recién casada de "Lección de cocina". Por mi parte, propongo verlo como un paso previo a la deconstrucción 
de esa asunción rolística, que nos permitirá reconducir su potencial educativo para la reflexión en el aula. En este sentido resultan iluminadoras las palabras de la propia Carpenter: "Rather than being examples of 'traditional' feminist writing, the three stories adopt an overtly anti-feminist stance in order to show women that they themselves are responsible for perceiving themselves as the objects of men's manipulation" (74). ${ }^{6}$ La narrativa de Castellanos nos reta, pues, a su discusión, a su propia desmitificación con su particular juego de máscaras (Mateu 1996).

\section{A MODO DE CONCLUSIÓN}

El recorrido por el relato inaugural de Álbum de familia, "Lección de cocina", nos ha mostrado sus posibilidades didácticas, tanto literarias como de reinterpretación de los roles sexuales y del matrimonio, cuya riqueza debería aprovecharse en la enseńanza, sobre todo como vector de significaciones simbólicas relevantes desde una perspectiva de género: la cocción de los filetes como correlato de la propia carne, de la relación de pareja, de la identidad y autenticidad de la recién casada, incluso del propio texto e historias de las mujeres, a través de la tradición de los recetarios y de las pócimas transmitidas como sabiduría femenina. En todos estos niveles simbólicos se percibe la historia de opresión de la mujer por parte de las estructuras del patriarcado, aterrizando en el caso concreto de la sociedad mexicana hasta bien pasada la mitad del siglo $\mathrm{xx}$, pero dejando un hueco a la esperanza: "Gracias a la sabiduría preservada, como si fuera guardada en las fotos de un álbum de familia, se forma una cofradía de integrantes desconocidas. El tiempo y la distancia, que las mantienen separadas, se desvanecen y las mujeres se sumen en una magia que las une y ampara" (Popovic: 109).

\footnotetext{
6 'En lugar de ser ejemplos de la escritura feminista 'tradicional', las tres historias adoptan una postura abiertamente antifeminista para mostrar a las mujeres que ellas mismas son responsables de percibirse a sí mismas como objetos de la manipulación de los hombres" (traducción mía). Se refiere, además de a "Lección de cocina", a otros relatos del mismo libro. Cfr. Urrutia.
} 


\section{BibLIOGRAFÍA}

Aparisi Miralles, Ángela. "Discursos de género: el modelo de la igualdad en la diferencia”, en Arbor, vol. 192, núm. 778, 2016: 303. Artículo disponible en línea en: <http://dx.doi.org/10.3989/arbor.2016.778n2006> [consultado el 20 de septiembre de 2016].

Asensi, Manuel. "Violencia, mito y sabotaje en Cóbraselo caro, de Élmer Mendoza", en Literatura Mexicana. Revista Semestral del Centro de Estudios Literarios, vol. XXV, núm. 1 (2014): 103-122.

Carpenter, Victoria. "Erasing Men from Album de familia by Rosario Castellanos", en EIAL, vol.21, núm. 2 (2010): 61-75. Artículo disponible en línea en: <http://dialnet.unirioja.es/descarga/articulo/3844947.pdf> [consultado el 22 de septiembre de 2016].

Castellanos, Rosario. Álbum de familia. México: Joaquín Mortiz, 1971.

Castellanos, Rosario. En la tierra de en medio, en Poesía no eres tú. Obra poética (1984-1971). México: Fondo de Cultura Económica, 1972.

Castellanos, Rosario. Mujer que sabe latín... México: Sep Setentas, 1973.

Castellanos, Rosario. El eterno femenino. México: Fondo de Cultura Económica, 1975.

Cuervo Hewitt, Julia. "Las huellas de sor Juana Inés de la Cruz en la obra de Rosario Castellanos”, en Romance notes, vol. 53, núm. 2 (2013): 135144.

Deleuze, Gilles y Félix Guattari. Mil Mesetas. Capitalismo y esquizofrenia. Valencia: Pre-textos, 1988.

Fishburn, Evelyn. "Dios anda en los pucheros: Feminist Openings in Some Late Stories by Rosario Castellanos", en Bulletin of Hispanic Studies, núm. LXXII (1995): 97-110.

Fox-Lockert, Lucía. "El eterno femenino en la obra de Rosario Castellanos", en Giuseppe Bellini (dir.). Actas del VII Congreso de la Asociación Internacional de Hispanistas. Centro Virtual Cervantes, 1980: 461-466. Artículo disponible en línea en: <http://cvc.cervantes.es/obref/aih/pdf/07/ aih_07_1_046.pdf> [consultado el 26 de julio de 2016].

Franco, E. "Dialéctica vida y muerte”, en Rosario Castellanos, Semblanza psicoanalitica. México: Plaza y Janés, 1984.

Girona, Nuria. "Mujeres que lloran, mujeres que fingen”, en S. Mattalia y N. Girona (eds.). Aun y más allá: mujeres y discursos. Caracas-Valencia: Ex Cultura (2001): 123-133.

Lindstrom, Naomi. "Rosario Castellanos: Pioneer of Feminist Criticism", en M. Ahern y M. S. Vásquez (eds.). Homenaje a Rosario Castellanos. Valencia: Albatros Hispanófila, 1980: 65-74. 
López-García-Torres, Rocío, y Elia SAneleuterio. "El valor de la palabra en la prevención de la violencia de género en contextos educativos", en Cuestiones de género: de la igualdad y la diferencia, núm. 11 (2016): 105-128. Artículo disponible en línea en: <http://dx.doi.org/10.18002/ cg.v0i11.3639> [consultado el 26 de julio de 2016].

Ludmer, Josefina. "Las tretas del débil”, en Patricia Elena González y Eliana Ortega (eds.). La sartén por el mango. Rio Piedras: Huracán, 1984: 4754.

Luongo Morales, Gilda. “'Lección de cocina’ de Rosario Castellanos: lo crudo y lo cocido en el ejercicio familiar/extraño del devenir sujeto femenino", en Cyber Humanitatis. Revista de la Facultad de Filosofía y Humanidades de la Universidad de Chile, núm. 17 (2001). Artículo disponible en línea en: <http://www.cyberhumanitatis.uchile.cl/index.php/ RCH/article/viewFile/8965/8882> [consultado el 26 de julio de 2016].

Lurie, Alison. No se lo cuentes a los mayores. Literatura infantil, espacio subversivo. Madrid: Fundación Germán Sánchez Ruipérez, 1998.

Martínez Lozano, C. Patricia. "Género, humor e ironía: la sonrisa de la escritora”, en Revista internacional de culturas y literaturas, núm. 1, 5256 (2013). Artículo disponible en línea en: <https://dialnet.unirioja.es/ servlet/articulo? codigo $=4663864$ \&orden $=1$ \&info=link $>$ [consultado el 20 de septiembre de 2016].

Maslow, Abraham. Motivation and Personality (2 $2^{\text {nd }}$ ed.). New York: Harper and Row, 1970.

Mateu Serra, Rosa. "Álbum de familia: la máscara como instrumento de desmitificación”, en Scriptura, núm. 12 (1996): 77-90.

Ocampo, A. "Rosario Castellanos y la mujer mexicana", en Homenaje a Rosario Castellanos, Cuadernos de Literatura, núm. 4. México: Universidad Iberoamericana, 1985.

Popovic Karic, Pol. "El doblez en Álbum de familia de Rosario Castellanos", en Centroamericana, vol. 23, núm. 1 (2013): 93-110. Artículo disponible en línea en: <https://dialnet.unirioja.es/servlet/ejemplar?codigo= 386591\&info=open_link_ejemplar $>$ [consultado el 20 de septiembre de 2016].

SAneleuterio, Elia. “'Cinco cabezas', de José Hierro: imagen, palabra y cuerpo fuera del tiempo", en Extravio. Revista electrónica de Literatura Comparada, núm. 4 (2009): 73-85. Artículo disponible en línea en: <https:// ojs.uv.es/index.php/extravio/article/view/2259/1858> [consultado el 26 de julio de 2016].

SAneleuterio, Elia. "Familia de cuentos. Sobre la narrativa breve de Rosario Castellanos", en Lejana. Revista critica de narrativa breve, núm. 2 
(2010a): 1-12. Artículo disponible en línea en: <http://lejana.elte.hu/ PDF_2/Elia_Saneleuterio.pdf> [consultado el 26 de julio de 2016].

Saneleuterio, Elia. "La imagen de la mujer en la obra de José Hierro", en María Mercedes González de Sande (cur.). Donne, identità e progresso nelle culture mediterranee. Roma: Aracne, 2010b: 429-440.

SANeleUterio, Elia. "Espacio público y territorialización", en La mujer en la literatura, la sociedad y la historia: identidad, cambio social y progreso en las culturas mediterráneas. La Coruña, 2010c: 503-511.

Saneleuterio, Elia. "Rosario Castellanos: la salsa del latín", en Manuel Fuentes y Paco Tovar (eds.). A través de la vanguardia hispanoamericana. Tarragona: Publicacions de la Universitat Rovira i Virgili, 2011a: 573584 .

Saneleuterio, Elia. "Hierro y Tagore frente a sus ataduras: la alucinación como espacio poético de libertad", en Pilar Caballero-Alías, Félix Ernesto Chávez y Blanca Ripoll Sintes (eds.). Del verbo al espejo. Reflejos y miradas de la literatura hispánica. Barcelona: Promociones y Publicaciones Universitarias, 2011b: 187-200.

Saneleuterio, Elia. "Progreso social o la europeización de España en una novela de Joan Oleza”, en Fidel López Criado (ed.). Europa a través de la literatura, el cine, y los medios de comunicación social. Santiago: Andavira Editora, 2011c: 189-196.

Soria Gutiérrez, Alejandra. "Metodología feminista, otro modo de ser humano y libre. Lectura de un cuento de Rosario Castellanos. 'Lección de cocina”, en Rafael M. Gasperín Gasperín y José Carlos Vázquez Parra (eds.). Narraciones éticas: desde la modernidad y la posmodernidad. Madrid: Plaza y Valdés, 2013: 55-81.

Subirats Martori, Marina. "Avances y retos en las políticas y en las prácticas de los géneros", en Educar. Especial 30 aniversario, 85-100 (2014). Artículo en línea disponible en: <http://dx.doi.org/10.5565/rev/educar.692> [consultado el 26 de julio de 2016].

Thibaudeau, Jean. "Entrevista con Roland Barthes", en Roland Barthes. El proceso de la escritura. Argentina: Caldén, 1974: 27-58.

Urrutia, Elena. "Rosario Castellanos. Despertar de la conciencia feminista", en Revista de la Universidad de México, núm. 16 (2005): 75-79. Artículo en línea disponible en: <http://dialnet.unirioja.es/servlet/articulo?codig $\mathrm{o}=2929597$ \&orden $=200228 \&$ info=link $>$ [consultado el 20 de septiembre de 2016]. 